\title{
Dispositional Knowledge-How versus Propositional Knowledge-That ${ }^{1}$
}

\author{
GREGOR DAMSCHEN
}

\section{Introduction}

Pelé knows how to play soccer; Anne-Sophie Mutter knows how to play the violin; and Michael Schumacher knows how to drive a car. All three have performed these activities successfully, over a long span of time, on a professional level. These kinds of human activity give credibility to the widely held idea that persons who know how to perform an action possess a stable disposition that enables them to successfully perform this action under certain, suitable conditions. Such a stable disposition to perform an intentional action is a practical ability or skill of a person. If knowledge-how is an ability, and therefore a dispositional property, then there is a form of knowledge that consists of a relation between a person and a practical ability. There are, however, other forms of knowledge than knowledge-how; there is, for instance, knowledge-that, a form much investigated by philosophers since Plato. Knowledgethat, however, does not express any relation between a person and a practical ability, but rather a relation between an epistemic subject and a proposition.

In regard to the above distinctions, two questions arise, which epistemologists have discussed for quite some time, at least ever since Gilbert Ryle attempted to sort out these issues.

Question 1: Is it at all true that someone who knows how to do something is disposed to perform an action under favorable conditions? Is knowledge-how a practical ability? Or is knowledge-how rather a hidden knowledge-that, and therefore also a relation between an epistemic subject and a proposition? Within the last few years, an influential article by Stanley and Williamson, who defend the intellectualist thesis that every type of knowledge

1 First and foremost I would like to thank Rainer Enskat and Eli Trautwein for extensive conversations and valuable comments on earlier drafts of this paper. Further thanks go to Dirk Effertz, Vittorio Hösle, Robert Schnepf, Dieter Schönecker, Karsten Stüber, and audiences in Wittenberg, Halle, Iowa, Notre Dame, Cologne, and Lucerne for helpful questions. 
is a knowledge-that, ${ }^{2}$ has stimulated a debate. In order to answer the first question complex appropriately one has to take into account the semanticpragmatic aspects of the use and meanings of the term 'knowledge-how' and its grammatical variations as well as the nature of knowledge-how.

Question 2: What is the connection between knowledge-how and knowledge-that? Is knowledge-how a form of knowledge in its own right, independent of knowledge-that, is it subordinate to knowledge-that, or is knowledge-that subordinate to it? Thus, the second question complex is aimed at determining the correlation between knowledge-how and knowledge-that; as well as the possible function that dispositional knowledge can have in the sphere of propositional knowledge.

I will deal with both questions in the course of my paper. In the first part, I argue that the term 'knowledge-how' is an ambiguous term in a semanticpragmatic sense, blending two distinct meanings: 'knowledge-how' in the sense of knowledge-that, and 'knowledge-how' in the sense of an ability. In the second part of my paper, I construe five alternative ways of correlating knowledge-that and knowledge-how in the sense of an ability. I will discuss each of these alternatives and will then argue in favor of one of them. For this purpose, I will develop a reductio ad absurdum argument which is very different from the one that Ryle constructed. ${ }^{3}$ This argument will show that knowledge-how is not a species of knowledge-that but rather that knowledgethat is a species of knowledge-how. More specifically, dispositional knowledge-how is at the core of propositional knowledge-that and accordingly should be understood to be at the center of epistemology. The general intellectualist assumption that all knowledge-how is a knowledge-that is as false as its opposite, that is, the anti-intellectualist assumption that no knowledge-how is a knowledge-that. The truth lies rather in the middle: many forms of knowledge-how are propositional knowledge-that, but some forms of knowledge-how are purely dispositional abilities. Since the main point of my paper will be the proof that every knowledge-that presupposes a certain dispositional knowledge-how, I primarily understand my thesis as a solution to the problem of construing the functional role of dispositional knowledge-how in relation to propositional knowledge-that.

2 Jason Stanley and Timothy Williamson (Stanley/Williamson 2001) have recently maintained, (taking their cue from Gilbert Ryle's reflections on the 'intellectualist legend' Ryle 1945/6 and 1949, 30-31]) that knowledge-how has been incorrectly understood as an independent form of knowing, more specifically as an ability, when it is, on the contrary, nothing but a species of knowledge-that.

3 Ryle 1945/6 and Ryle 1949, 30-31. 


\section{Two Kinds of Knowledge}

Syntactically the verb 'to know' in English permits very different sentential complements. One can, for example, know that such-and-such is the case. But one can also know where something is, when something occurred, who has something, what someone has, where someone comes from, where someone is going to, why, whatever... for, and how come something happens, how high or how long something is, how fast someone runs, and so on. These examples of knowledge sentences containing embedded questions seem to be very intimately related to knowledge-that, in that they seem, like knowledge-that, to express a relation between an epistemic agent and a proposition or fact. ${ }^{4}$ To briefly clarify this point, take the following two examples: If someone says, she knows where St. Peter's Cathedral is located, she in fact is saying nothing more than that she knows that St. Peter's is located at such-and-such a location. And if someone says, he knows, how tall the Eiffel Tower is, he is saying nothing more than he knows that the Eiffel Tower has this or that height. These two small transformations of a knowing-where- and a knowing-how-statement into a knowing-that-statement can be performed analogously with the just mentioned types of knowledge sentences. Has the common core of knowledge statements thus been found? Is every knowing a hidden knowledge-that?

Things get more complicated if another sentential complement of 'to know' is taken into account: knowing how to do something. Although this expression, looked at syntactically, also contains the knowledge predicate and an embedded question, which begins with 'how' - like the expression 'know how tall the Eiffel Tower is' - there are cases in English where, in sentences of the type 'I know how such-and-such is done,' we do not want to express a relation between an epistemic agent and a proposition, but a relation of a conscious agent to a set of personal dispositions or abilities to successfully complete acts. ${ }^{5}$ If this non-propositional form of knowledge is admitted, a search for a uniform definition of the term 'knowledge,' which should be the goal of the theory of knowledge, has first to answer the above questions about the nature of knowledge-how. Thus, every search for a definition of knowledge must address the following two questions: first, what is knowledge-how and second, what is the connection between knowledge-how and knowledge-that? ${ }^{6} \mathrm{We}$

$4 \quad$ Cf. Karttunen 1977.

5 The Greek noun episteme, that gives epistemology its name 'theory of knowledge,' has a meaning in the sense of knowledge, how something is done, and in the sense of knowledge, that such-andsuch is the case. Cf. Liddell/Scott 1996, 660: "acquaintance with a matter, understanding, skill... 2. professional skill... II. generally knowledge... 2. scientific knowledge, science...” For Plato's types of knowledge see Damschen 2003.

6 Only recently has interest in these questions returned more intensively subsequent to Gilbert Ryles exemplary reflections in his "Knowing How and Knowing That" (Ryle 1945/6) and in his 
will see that we can answer the second question without already having a comprehensive answer to the first question.

\section{An Ambiguity in the Term 'Knowledge-How'}

There is a distinction between knowing how to do something and knowing that something is the case. This distinction is not merely syntactic; thus one cannot analyze it by analyzing the syntax of the embedded indirect questions in knowledge statements. The distinction I have in mind is a semanticpragmatic one. For 'knowing how' is specifically used to express the relation between an epistemic agent and a set of dispositions or abilities, and not the relation between an epistemic agent and a proposition. In order to decide whether a speaker's use of a 'knowing how' phrase corresponds to our canonical explanation of the phrase (that is, expressing the relation of an agent to an ability) one should substitute the phrase "knowing how to do such-andsuch" with expressions such as "able to do such-and-such" or "disposed to do such-and-such." If the speaker accepts the substitution, we can assume that he does not equate knowing how, here, with knowing that. The truth conditions for a sentence like "I know how one should play the violin" consist in the fact that the speaker, who makes this claim, possesses in fact the practical skill to play the violin and, under suitable conditions, plays the violin successfully. I call this type of non-propositional knowledge-how in the following 'dispositional knowledge-how'. French, German, or Latin speakers have their own native syntactic construction available to form equivalents to the English dispositional knowledge-how phrase, 'I know how to do this.' In these three languages, the verb 'to know' is joined to an expanded infinitive clause: 'Je sais faire quelque chose,' 'Ich weiß, das-und-das zu tun,' 'aliquid facere scio.' ${ }^{7}$ German speakers explicitly refer to a 'Wissen-zu,' [knowledge-to] when they mean knowledge-how in the sense of a practical ability. Since the aim of epistemology is to study knowledge in general and not merely knowledge constructions capable of being expressed in the knowledge predicate in English syntax, we must take syntactical information obtained from other languages very seriously. The above substitution test shows very clearly that, in English too, the expression 'knowledge-how' can refer to something which is not a knowledge-that.

The Concept of Mind (Ryle 1949). For example the former question was most recently analyzed by Hawley 2003 and Enskat 2005, and the latter by Stanley/Williamson 2001, Koethe 2002, Enskat 1998, 2003, 2005, Damschen 2005, Noë 2005, Hetherington 2006, Bengson/Moffett 2007, Lihoreau 2008, Williams 2008, and Adams 2009. Another approach which remains valuable is that of Polanyi 1958.

7 Cf. Rumfitt 2003. 
Accordingly, there are modes of use of the verb 'knowing-how' by means of which the speaker expresses that he possesses a practical ability. The opponents of the view that there is knowledge-how which is a practical skill, however, do not yet admit defeat. They often propose a counter-argument like the following: ${ }^{8}$ Let us assume that a master violinist like Anne-Sophie Mutter knows how one should play the violin. She has sufficiently often played the violin in the past, so that we are entitled to make this ascription. Let us assume furthermore that she lost both hands in a bad accident. Then we have the case of a violinist who does know how one should play the violin but is actually unable to play the violin. According to the opponents of dispositional knowledge-how, this case clearly shows that to know how one performs an action is not the same as to have an ability to perform the action, for there are cases in which someone does know how one performs a certain action, but does not possess the corresponding ability.

I doubt that this example or similar examples of this type support the view that knowledge-how is not the same as having an ability. Of course, there may be the case where Anne-Sophie-Mutter knows how to play the violin and nevertheless is not able to play the violin at the moment, because she is sleeping at the moment or because no violin is available, although she would like to play it. Nobody, however, would therefore claim that AnneSophie Mutter, in these periods of time, lost her ability to play the violin, and then regains it suddenly by means of a miraculous act when she wakes up or a violin appears. Neither of these two cases shows in any way that to know how one should play the violin is not the ability to play the violin. The same considerations also apply to the case where Anne-Sophie Mutter loses both hands: a situation that is logically comparable to the case where no violin is available at the moment. In both cases does she know how to play the violin and possesses an ability to play the violin without being able to play the violin at that very moment. The realization of an ability always presupposes certain conditions that must be satisfied so that the ability can be carried out successfully. These conditions can be external conditions that do not have to do with the bearer of the ability, e.g. the lack of a violin when one wants to play the violin. However, these conditions also can be conditions that are connected with the body of the bearer of an ability, e.g. if a violinist has lost both hands or, to assume a less drastic case, has perhaps such a strong influenza that she cannot hold the violin. ${ }^{?}$

Practical knowledge and practical abilities have, therefore, four important properties: ${ }^{10}$

8 Cf. Stanley/Williamson 2001, 416.

9 Cf. Noë 2005, 282-283.

10 Cf. Noë 2005, 284-286. 
1. They are always the knowledge of someone, i. e., they are the knowledge of a person. In this regard, one can call them personal knowledge. For practical abilities do not exist independently, but require a bearer who is able to perform intentional actions.

2. The second property of practical knowledge is connected directly with its first property. Normal abilities are embodied. I presume that persons who we know have a body. I do not want to commit myself to the view that there are no persons without bodies. But it is true anyway that the cases of knowledgehow, which we look at, are always cases where the bearer of a knowledge-how is a person who has a body. The acquisition of practical skills changes our body and we perform our skills by means of our body.

3. The third property of practical knowledge is that it is situated. Dispositional knowledge can only be realized if certain external conditions are fulfilled. Pelé cannot play soccer if no football is available, and Michael Schumacher cannot drive any formula-one car if its tires are slashed. Basically, every proposition like 'Somebody S knows how one X-s' has to be completed in the following way: 'Somebody S knows how to X under circumstances C.'

4. The fourth property of practical knowledge is to be disposed to perform an action successfully. If Anne-Sophie Mutter cannot successfully play the violin or if Michael Schumacher cannot successfully compete in a car race, one could neither say of Mutter that she knows how one should play the violin nor of Schumacher that he knows how one should race cars.

So, knowledge-how is a personal, embodied and situated ability to successfully realize an action. Our analysis thus has shown that there are manifestations of 'knowledge-how' that are instantiated when someone possesses a practical ability.

The above canonical instances of 'knowing how' (that is, knowing how as an ability) are, however, not the whole story. For, confusingly, in English and in the other languages mentioned, there is a second, completely different use of the expression 'knowledge-how' with which a relation between an epistemic agent and a proposition can, indeed, be expressed. Again, our semantic test is quite simple. One must ask the speaker who says 'I know how one does such-and-such' whether the statement he makes can be rendered straightforwardly and without distortion as 'I know, that one must do suchand-such in order to act in this or that manner.' If he affirms this, then he wants to say that he is the carrier of a propositional knowledge-how. Furthermore, if the speaker is able to list a sequence of appropriate steps to act in this or that manner he is indeed a carrier of such propositional knowledge-how. Thus, depending on the intention of the speaker, sentences such as

(1) I know how to drive a car 
can have firstly (1a) a non-propositional and dispositional meaning, e.g. as the answer of an active driver to the question of whether he has the ability to drive a car successfully. Yet, secondly the sentence can also have (1b) a propositional meaning, e.g. as the answer of a driving instructor to the question whether he can articulate in propositional form the actions necessary to control a car, the relevant theoretical knowledge, and the most important rules of the road. Finally the sentence can thirdly (1c) have both meanings simultaneously, i.e. the dispositional and the propositional, e.g. as the answer of a driving instructor to the question whether he himself is able to drive a car and whether he also can communicate to his students in propositional form everything that one has to do in the process. ${ }^{11}$ The last sense of knowledge-how in the sense of a hybrid between dispositional and propositional knowledge-how is the meaning that one comes across most frequently as David Lewis accurately observed: "It would be feeble, I think, just to say that we're fooled by the ambiguity of the word 'know': we confuse ability with information because we confuse knowledge in the sense of knowing-how with knowledge in the sense of knowing-that. There may be two senses of the word 'know,' but they are well and truly entangled. They mark the two pure endpoints of a range of mixed cases. The usual thing is that we gain information and ability together. If so, it should be no surprise if we apply to pure cases of gaining ability, or to pure cases of gaining information, the same word 'know' that we apply to all the mixed cases."12

Thus, we have three instances of knowledge-how. To keep them easily apart in the following, I will use subscripts to distinguish between them:

(a) knowledge-how , that is dispositional and non-propositional knowing how;

(b) knowledge-how , that is knowing how that can be articulated in terms of propositions;

(c) knowledge-howh, that is knowing how as bybrid.

It was no doubt the propositional use of knowledge-how or knowledge-how $_{\mathrm{h}}$ which led philosophers to their general claim that every knowledge-how is a

11 To formulate this insight more precisely I give the relevant truth conditions for each of the three cases:

(1a) (1) is true iff the speaker of the sentence (1) has the personal ability to successfully drive a car.

(1b) (1) is true iff the speaker of the sentence (1) explicitly knows that one must do such-andsuch to drive a car.

(1c) (1) is true iff both (1a) and (1b) are met.

12 Lewis 1999 , here p. 289. 
knowledge-that. ${ }^{13}$ For the purpose of this paper it is only important to recognize that the dispositional form of knowledge-how in the sense of a practical ability (knowledge-howd) exists. ${ }^{14}$

\section{Five Alternative Answers}

Asking whether and how knowledge-how in the dispositional sense (knowlege-how $\mathrm{d}$ ) and knowlege-that in the propositional sense are semantically related yields the following five alternatives:

(A1)Knowledge-how is a species of knowledge-that, i.e.:

knowledge-that is a necessary condition for knowledge-how $\mathrm{d}$.

(A2)Knowledge-that is a species of knowledge-how ${ }_{d}$, i.e.:

knowledge-how $_{\mathrm{d}}$ is a necessary condition for knowledge-that.

(A3)Knowledge-how and knowledge-that are extensionally equivalent.

(A4)Knowledge-how and knowledge-that have a common intersection.

(A5)Knowledge-how $\mathrm{d}$ and knowledge-that are completely distinct.

These five alternative ways of thinking about the relation between knowledgehow and knowledge-that correspond to alternative strategies in looking for a definition of knowledge. ${ }^{15}$ (S1) If we think of all forms of knowledge as propositional knowledge, we must be convinced of having found a good argument for alternative A1.16 (S2) On the other hand, if we opt for alternative A2, we must place the search for a definition of knowledge-how at the center of our epistemological reflections; knowledge-that would then only be a spe-

13 E.g. Hintikka 1975, or Stanley/Williamson 2001.

14 Cf. on this also Ryle 1949, Rumfitt 2003, Rosefeldt 2004, Noë 2005, 284, Lihoreau 2008, and Williams 2008.

15 Asking whether and how knowledge-how in the propositional sense (knowledge-how $)$ and knowledge-that in the propositional sense are semantically related yields at least the following alternatives:

(B1) Knowledge-how is a species of knowledge-that.

(B2) Knowledge-that is a species of knowledge-howp.

(B3) Knowledge-how $w_{p}$ and knowledge-that are extensionally equivalent.

(B4) Knowledge-how $w_{\mathrm{p}}$ and knowledge-that have a common intersection.

(B5) Knowledge-how $\mathrm{p}$ and knowledge-that are completely distinct.

Although alternative B1 seems to be the right answer, deciding this claim is not the subject of this paper.

16 Cf. e.g. Hintikka 1975, 3: “... all of the different constructions in terms of the verb 'know' can be reduced ... to the sense in which the nature of knowledge as a propositional attitude is most explicit ... the 'knowing-that'." 
cies or subcategory of knowledge-how. ${ }^{17}$ (S3) If we choose alternative A3, we must stipulate that an extensional definition of knowledge-that be identical with an extensional definition of knowledge-how. (S4) Alternative A4 presents us with a non-uniform definition for the term 'knowledge' encompassing three equally valid and distinct definitions of a form of pure knowledgethat, a form of pure knowledge-how and a mixed form of the two. (S5) Finally, alternative A5 like A4 presents us with a non-uniform definition of the term 'knowledge' entailing two, rather than three, equally valid and distinct definitions of knowledge-how and knowledge-that.

Most epistemologists, without always stating it explicitly or perhaps having consciously thought about it, follow strategy S1 or S5. But no matter, our reflections up to this point have shown that those who would like to provide a definition of knowledge can only begin their work in a methodologically controlled manner if they have found at least one good argument for one of the five listed alternatives and, at the same time, good arguments against the remaining four alternatives.

Unfortunately there have been only few arguments which could make the decision between these five alternatives easier. The most familiar argument against alternative A1 is Gilbert Ryle's argument against what he calls the 'intellectualist legend'. ${ }^{18}$ As we have seen, Ryle's "intellectualist legend" argument against A1 has recently been disputed by Stanley and Williamson. ${ }^{19}$ However, their argument for A1 is not satisfactory. ${ }^{20}$ For it is mainly based on unconvincing linguistic reflections regarding the syntactic relatedness of knowledge-how and knowledge-that sentence constructions in the English language, ${ }^{21}$ which cannot support a broader metaphysical project of finding a general definition of knowledge. ${ }^{22}$ For alternative A5 there have been weakly plausible arguments, genealogically rooted in Ryle's original argument. ${ }^{23}$ There have also been a few arguments for saying - vide alternative A 2 - that some-

17 Cf. e.g. Colin McGinn [McGinn 1984], here p. 529: "And once we take on the responsibility of confronting the whole family of knowledge locutions, it is by no means guaranteed that propositional knowledge will emerge as fundamental: perhaps the core notion will attach most directly to some other locution, so that knowledge-that comes out as a species of some more basic type of knowledge."

18 Ryle 1945/6 and Ryle 1949, 30-31.

19 Stanley/Williamson 2001, 412-417. Whether their reconstruction in fact grasps Ryle's original argument will have to remain untreated here. Cf. on this Rosefeldt 2004 and Noë 2005.

20 See Stanley/Williamson 2001, 417-444.

21 See Rumfitt 2003.

22 Furthermore their concept of knowledge-how as a relation between an epistemic agent and practical propositions leads to unacceptable consequences. See Koethe 2002 and Schiffer 2002.

23 Cf. e.g. Carr 1979; Carr 1981; Devitt 1996, 52; Putnam 1996, xvi; Lewis 1999, 288. 
one who knows that $p$ has the capacity to state correctly that $p \cdot{ }^{24}$ However, these claims fail since we can imagine someone who, stating that $p$, is really just guessing that $p$ is the case. If, by chance, $p$ is actually the case, he correctly states that $p$ and a fortiori he has the capacity to state correctly that $p$, but we would not say that he knows that $p$. Moreover, if having a capacity to state $p$ correctly involves reasons for $p$, these reasons will contain propositional knowledge-that. Thus, any reducing of knowledge-that to knowledge-how will prove to be circular. ${ }^{25} \mathrm{I}$ have found no explicit arguments for assumptions A3 or A4 in the philosophical literature.

I will now introduce a new argument against A1 which, in a very broad sense, follows in the tradition of Ryle's original argument. I, however, will make use of very different premises. I try to accomplish two objectives with my argument: First, as a reductio ad absurdum it shows that the claim that dispositional knowledge-how $\mathrm{w}_{\mathrm{d}}$ is a species of knowledge-that is untenable; second, using the first and the last of its premises we can construct a hypothetical syllogism that shows that knowledge-that is a subcategory of dispositional knowledge-how . $_{\text {. }}$

\section{The Species-of-Knowledge Argument}

The argument against alternative A1, which I call the species-of-knowledge argument, leads formally speaking to a reductio ad absurdum. It thus includes premise A1, which will be refuted, and two other premises P1 and P2:

(P1) For all epistemic agents $S$, for all intentional acts F: If $S$ regularly and successfully completes the intentional act $F$ (which $S$ completed earlier sufficiently often, regularly and successfully), then $S$ knows how to complete act $F$.

(A1)For all epistemic agents $S$, for all intentional acts $F$, there is at least one proposition $\varphi$ : If $S$ knows how to complete act $F, S$ knows that $\varphi(F)$.

(P2) For all epistemic agents $S$, for all propositions $\varphi$, there is at least one intentional analysis act $U$ : If $S$ knows that $\varphi$, then $S$ completed the intentional analysis act $U$ sufficiently often, regularly, and successfully, whether $\varphi$ is the case, or whether not- $\varphi$ is the case.

24 Hartland-Swann 1956 and 1957, Roland 1958. For a new argument for assumption A2 see now also Hetherington 2006.

25 See the critique on Hartland-Swann by Ammerman 1957. 
Let us start with premise A1 that in the end will be refuted with the help of the species-of-knowledge argument. According to A1, any knowledge bow act $F$ is completed can be traced back to the attitude of knowledge in relation to the contents of a specific practical proposition $\varphi(F)$. This practical proposition $\varphi(F)$ states, that such-and-such must be done to complete act $F$. Accordingly, knowing how to do $F$ would be nothing but to know that such-andsuch must be done in order to do F. But this would imply that every knowledge-how would be nothing but a kind of knowledge-that.

Premise P1 states a sufficient, not a necessary condition for dispositional knowledge-howd. Even though a comprehensive definition of knowledgehow $_{\mathrm{d}}$ continues to be a desideratum, ${ }^{26}$ for the purpose of the current argument it is not necessary to have such a definition at hand. Premise P1 can be made plausible as follows: it can be straightforwardly admitted that someone who was sufficiently often engaged regularly and successfully in an intentional act $F$, also has the ability to complete act $F$. The practice of a regular and successful act is a sufficient condition for a person having the corresponding ability. The condition that it must involve an intentional, i.e. intentional and consciously planned act, rules out activities performed by robots or nonpersonal entities. For none of us would say that a robot in a strict sense 'knows' how to do such-and-such. It may certainly have a disposition towards doing something very specific, but a knowledge-how seems to be more than a mere disposition to do something. It seems also to involve at least a relation of the agent to himself, his disposition, and his conscious act. For our earlier analysis has suggested that knowledge-how is a personal, embodied and situated ability to successfully realize an action.

However, the reason premise P1 contains the explicit condition that only an adequately large number and only a successful realization of intentional actions can be sufficient for the ascription of a knowledge-how is a response to the objection of some philosophers (most notably, Stanley and Williamson) that the fact that someone performs a non-intentional action does not imply that he has a knowledge-how. Stanley and Williamson discuss the following example:

(2) If Hannah digests food, she knows how to digest food. ${ }^{27}$

And they assert that the proposition is false for the following reasons: "Digesting food is not the sort of action one knows how to do." I agree in a certain way: Indeed, Hannah cannot know how to digest food. But the reason for that is not (as Stanley and Williamson assert) that digesting food is a spe-

26 See Hawley 2003 and Williams 2008.

27 Stanley/Williamson 2001, 414. 
cial and mysterious sort of non-intentional action in Hannah for which a corresponding knowledge-how does not exist. The reason is simply the fact that digesting food in Hannah is not an action that Hannah performs or could perform at all: neither a 'non-intentional action' (whatever this may be) nor an intentional action. It is not Hannah who digests food but her digestive system, and in fact in her and for her. ${ }^{28}$ Neither digesting nor breathing nor the process of metabolism is something a person can actively do. These processes take place in and for persons, but they are not performed by persons as actions. In this regard, the funny thing about the proposition "If Hannah digests food, she knows how to digest food" seems to be that it is true, for the antecedent of the proposition is false, because it is not Hannah who digests the food. There are additional examples of this type, such as the one in which Hannah buys lottery tickets and wins. The proposition that is supposed to show that there are actions that do not imply any knowledge-how is as follows:

(3) If Hannah wins a fair lottery, she still does not know how to win the lottery, since it was by sheer chance that she did so.

Admittedly, there is probably no knowledge how one wins the lottery, but Hannah here does not perform an action which is sufficient for a knowledgehow. For to win the lottery is not an action Hannah could perform. Hannah is able to perform many actions: She can go to the lottery shop, she can buy a lottery ticket. However, winning the lottery is not an action Hannah can actively perform, but rather an event that happens to Hannah. In this respect, this example does not show that there are actions that do not presuppose any knowledge-how, because it fails to meet the condition that the actions should be (intentional) actions of a person. ${ }^{29}$

Of course, there are actions which do not imply knowledge-how. These are frequently actions that are performed in acquiring a new ability. For example, the sentence "Arma virumque cano Troiae qui primus ab oris Italiam fato profugus Laviniaque venit litora" could be correctly pronounced purely by chance by the beginning Latin student. The action is thus successfully performed from the perspective of a third person, but perhaps the lucky Latin student cannot consistently reproduce his correct pronunciation. But if the speaker successfully and correctly pronounces the sentence "Arma virumque cano Troiae qui primus ab oris..." - not only on a single day, but for a longer period of time, not only in a single situation, but in various situations, not only this sentence of the language, but also additional sentences - then we

28 Cf. Noë 2005, 279.

29 Cf. Noё 2005, 280. 
can assume that he has acquired the ability of correctly pronouncing this sentence. Given a correspondingly great number of successful performances of correctly pronouncing the sentence, we will be inclined to ascribe a corresponding ability to the speaker. Premise P1 does not say more; but it also does not say less.

Premise P1 should, however, not be understood as saying that there are only abilities if they are performed regularly. It is certainly imaginable that there are certain abilities which under favorable conditions, if at all, can only be performed once in a lifetime (for example, being courageous when saving someone's life). The premise P1, moreover, is implicitly accepted by Stanley and Williamson. ${ }^{30}$ They accept that performing an action $F$ implies that the person who performs it also knows how one performs the action, but only if the actions in question are intentional actions. So Stanley and Williamson accept premise P1, although, unlike myself, they accept the truth of the premise A1. The acceptance of P1 thus appears to be independent of the acceptance or rejection of $\mathrm{A} 1$.

\section{Premise P2: Knowledge-That presupposes some Kind of Analysis}

Premise P2 formulates a necessary condition for knowledge-that: whoever knows that $p$ is the case has also analyzed whether $p$ or not- $p$ is the case. I think that this premise states succinctly our epistemic basic intuition expressed by the Gettier cases that we would not consider a belief that was merely accidentally true to be knowledge. ${ }^{31}$ But how does one advance from merely accidentally true belief to a non-accidentally true belief? To arrive at a non-accidentally true belief that $p$ is the case, we must firstly analyze in a specific manner whether $p$ is true or not- $p$ is true. ${ }^{32}$ This means that we must complete some kind of analysis program. This analysis program contains a set of analysis acts. But if we want to complete this analysis program successfully we must be able to distinguish truth from falsehood at each step of the program. For this purpose we must have an ability, a "truth-discriminating capacity." 33

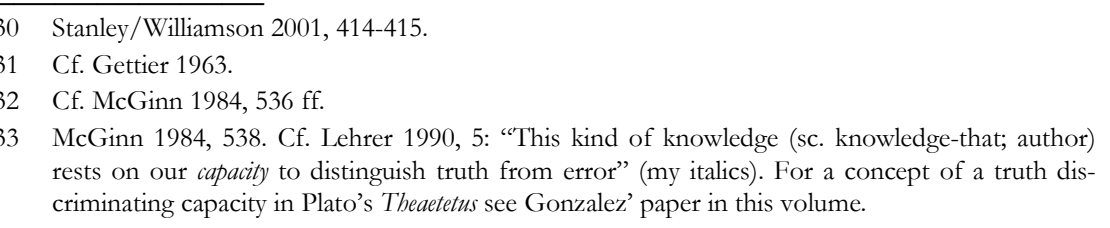


Colin McGinn, who (in accord with Austin and Goldman) represents a special version of a reliability theory of knowledge, articulates the idea of this type of truth-discriminating capacity as follows: "The guiding idea of the theory is simple: to say that a person $S$ is globally reliable with respect to a range of propositions is to say that $S$ can discriminate truth from falsehood within that range of propositions; global reliability is a capacity to tell the difference between true propositions and false ones within some given class of propositions. We then say that $S$ knows that $p$ just if his (true) belief that $p$ is acquired by the exercise of a capacity to discriminate truth from falsehood within some relevant class $\mathrm{R}$ of propositions." 34

This ability has to be understood as being realized in very many forms, since its object ranges over the spectrum of all propositions. If we examine this ability more closely, we can see that it comprises some or all of the following five sub-abilities: 1 . the ability to pose questions and to recognize possible answers to these questions as appropriate while others are rejected as inappropriate (question-based knowledge), 2. the ability to use categories appropriately (knowledge of categories), 3. the ability to make judgments (judgment knowledge), 4. the ability to complete thinking acts of a more complex nature (ability of connecting judgments), and 5. being able to complete physical acts (practical knowledge).

The mere fact of being able to distinguish true propositions from false propositions, however, does not suffice to ascribe a specific knowledge-that to someone. It also involves him/her not only having this ability in the relevant case but also him/her having in fact successfully realized it. To know that $p$ is the case one, therefore, must in fact have found out that $p$ is the case. ${ }^{35}$ Before we can know that $p$ is true, we must first successfully complete the truth analysis program with our attention on $p$. This successfully completed analysis program which produces the result that either $p$ or not- $p$ is true, is thus the smallest common denominator of what must at least be added to a true belief if it is not to be merely accidental.

The exact nature of the analysis program and the knowledge-howd that is required for it depends, however, on the situation: the truth analysis can consist in personally traveling to Rome and going to St. Peter's Square if one wants to know whether it is really true that St. Peter's is in Rome, or alternatively - to take Goldman's well-known but extremely artificial example examining the object that looks like a barn from a distance from the inside if one wants to distinguish fake barns from real barns. ${ }^{36}$ But such intentional

34 McGinn 1984, 536-537.

35 Cf. Ryle 1971 (1945/6), 224: "To know a truth I must have discovered ... it"; Clark 1963, 48: "Knowing implies having found out." Enskat 1998 and 2005 discusses extensively the idea that propositional knowing-that rests on a dispositional knowing-how.

36 Cf. Goldman 1992, 86 ff. 
analysis acts are necessary as part of an analysis program not only in the field of empirical knowledge, but also in regard to non-empirical knowledge. For example, if one wants to know whether $5+7=12$, the relevant analysis program consists in calculating the mathematical equation sufficiently often and successfully oneself in an appropriate way. ${ }^{37}$

\section{The Reductio ad absurdum}

How and why do the three premises A1, P1, and P2 together yield a reductio ad absurdum? If premise A1 is plausible and true then there should be no case in which A1 together with other plausible and true premises leads to absurd consequences. Let us take as an example the special case of an act $F$, e.g. that Albert Einstein walks from his house to his office in Princeton, implying that he also successfully arrives and has walked sufficiently often and successfully in the past from his house to his office. In addition, the following two assumptions are made:

Z1: Einstein's walk from his house to his office is an intentional act $F_{1}$,

Z2: For all $x$ : If $x$ is an analysis act $U$, with whose help one can analyze whether $\varphi$ or not $\varphi$, then $x$ is an intentional act $F$.

Then, assuming the truth of the three premises A1, P1 and P2, the following vicious regress results:

(1) Einstein walks from his house to his office.

[assumption]

(2) Einstein $F_{1}$-s.

$[1, \mathrm{Z1}]$

(3) Einstein knows how to $F_{1}$.

$[2, \mathrm{P} 1]$

(4) Einstein knows that $\varphi\left(F_{1}\right)$.

$[3, \mathrm{~A} 1]$

(5) Einstein completed analysis act $U_{1}$.

$[4, \mathrm{P} 2]$

(6) Einstein $\mathrm{F}_{2}$-s.

$[5, \mathrm{Z} 2]$

(7) Einstein knows how to $F_{2}$.

$[6, \mathrm{P} 1]$

(8) Einstein knows that $\varphi\left(F_{2}\right)$.

[7, A1]

(9) Einstein completed analysis act $U_{2}$.

(10) Einstein $F_{3}$-s.

$[9, \mathrm{Z} 2]$

and so on and so forth.

Thus if premises P1 and P2 are accepted and it is also assumed that A1 is true, the result is a vicious regress so that the act $F_{1}$ never could have oc-

37 The premise P2 is at least implicitly contained in internalist interpretations of the classic third condition of knowledge, the justification condition. 
curred. But that is absurd, for according to our assumption Einstein in fact does walk from his house to his office. Since we presuppose that premises P1 and P2 are true, premise A1 must therefore be false. Consequently, it is not the case that dispositional knowledge-how is a species of knowledge-that.

\section{Knowledge-That: a Species of Knowledge-How}

If $A 1$ is false, A2, A4 or A5 can still be true (except A3, which is false if A1 is false). But someone, who holds premises P1 and P2 to be true, must also hold A2 to be true. For P2 states that someone who knows that $p$ is the case has also analyzed whether $p$ or not- $p$ is the case sufficiently often, regularly, successfully and intentionally. And P1 states that someone who regularly and successfully completes the intentional act $F$ (which he earlier has sufficiently often, regularly and successfully completed) also knows d how act $F$ is completed. If the analysis of whether $p$ or not- $p$ is the case is itself an intentional act $F$ (let's call this premise $G$ ), then this act presupposes a knowledge-how d. $_{\text {. }}$ All of this leads to the following hypothetical syllogism:

(P2) If $S$ knows that $p$, then $S$ has completed sufficiently often, regularly and successfully the intentional analysis act $U$, whether $\varphi$ is the case, or whether not- $\varphi$ is the case. $\quad[\mathrm{A} \rightarrow \mathrm{B}]$

(G) If $S$ has completed sufficiently often, regularly and successfully the intentional analysis act $U$, whether $\varphi$ is the case, or whether not- $\varphi$ is the case, then $S$ has completed sufficiently often, regularly and successfully an intentional act $F(p) . \quad[B \rightarrow C]$

(P1) If $S$ has completed sufficiently often, regularly and successfully an intentional act $F(p)$, then $S$ knowsd how to complete an intentional act $F(p)$.

$[\mathrm{C} \rightarrow \mathrm{D}]$

Therefore, (A2) If $S$ knows that $p$, then $S$ knows $_{d}$ how to complete an intentional act $F(p)$.

$[\mathrm{A} \rightarrow \mathrm{D}]$

Hence, someone who holds P1, P2 and G true must also hold A2 true. But if A2 is true, dispositional knowledge-how and propositional knowledge-that have neither an intersection nor are they completely distinct. As a consequence, A4 and A5 are false. Hence A1, A3, A4 and A5 are false, A2 is true. Dispositional knowledge-how is a necessary condition for propositional knowledge-that, and propositional knowledge-that is a species or subcategory of dispositional knowledge-how d. $^{2}$ 


\section{Conclusion}

Let us summarize the results of my considerations: It has been shown that there are two types of knowledge-how: the first kind depends on propositional knowledge-that (knowledge-how $\mathrm{w}_{\mathrm{p}}$ ), and the second kind is a nonpropositional form of knowledge-how in the sense of a disposition or ability (knowledge-how $\mathrm{d}$ ). Moreover, the species-of-knowledge argument helped to demonstrate that dispositional and non-propositional knowledge-how $\mathrm{w}_{\mathrm{d}}$, and not knowledge-that, is basic for our concept of knowledge. Examined more

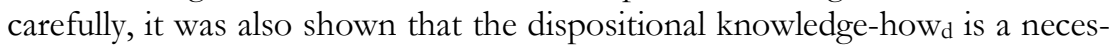
sary condition for knowledge-that, hence knowledge-that is a species of the dispositional knowledge-how . And finally, it has been shown that the relation between both specified forms of knowledge can be determined without presupposing in advance a complete and thoroughly accepted definition of propositional knowledge-that or dispositional knowledge-how .

\section{Literature}

Adams, Marcus P. 2009. "Empirical Evidence and the Knowledge-That/Knowledge-How Distinction." Synthese 170: 97-114.

Ammerman, Robert. 1957. “A Note on 'Knowing That'." Analysis 17: 30-32.

Bengson, John, and Moffett, Marc A. 2007. "Know How and Concept Possession." Philosophical Studies 136: 31-57.

Carr, David. 1979. "The Logic of Knowing How and Ability.” Mind 88: 394-409.

Carr, David. 1981. "Knowledge in Practice.” American Philosophical Quarterly 18: 53-61.

Clark, Michael. 1963. "Knowledge and Grounds: A Comment on Mr. Gettier's Paper." Analysis 24: 46-48.

Damschen, Gregor. 2003. "Grenzen des Gesprächs über Ideen. Die Formen des Wissens und die Notwendigkeit der Ideen in Platons Parmenides." In Platon und Aristoteles - sub ratione veritatis. Festschrift für Wolfgang Wieland zum 70. Geburtstag, ed. Gregor Damschen, Rainer Enskat, and Alejandro G. Vigo, 31-75. Vandenhoeck \& Ruprecht: Göttingen.

Damschen, Gregor. 2005. "Ist Wissen-dass eine Unterart von Wissen-wie?” [Is Knowledge-That a Species of Knowledge-How?]. In Philosophische Perspektiven. Beiträge zum VII. Internationalen Kongress der Österreichischen Gesellschaft für Philosophie, ed. O. Neumaier, C. Sedmak, and M. Zichy, 290-295. Frankfurt am Main / Lancaster: ontos.

Devitt, Michael. 1996. Coming to Our Senses. New York: Cambridge University Press.

Enskat, Rainer. 1998. "Authentisches Wissen. Was die Erkenntnistheorie beim Platonischen Sokrates lernen kann.” In Amicus Plato magis amica veritas. Festschrift für Wolfgang Wieland zum 65. Geburtstag, ed. R. Enskat, 101-143. Berlin: de Gruyter.

Enskat, Rainer. 2003. "Ist Wissen der paradoxe epistemische Fall von Wahrheit ohne Wissen? Platon, Gettier, Sartwell und die Folgen." Zeitschrift für philosophische Forschung 57: 431-445.

Enskat, Rainer. 2005. Authentisches Wissen. Prolegomena zur Erkenntnistheorie in praktischer Hinsicht. Göttingen: Vandenhoeck \& Ruprecht. 
Gettier, Edmund. 1963. "Is Justified True Belief Knowledge?” Analysis 23: 121-123.

Goldman, Alvin. 1992. Liaisons. Philosophy Meets the Cognitive and Social Sciences. Cambridge/Mass.

Hartland-Swann, John. 1956. "The Logical Status of 'Knowing That'." Analysis 16: 111115.

Hartland-Swann, John. 1957. "Knowing That - A Reply to Mr Ammermann.” Analysis 17: 69-71.

Hawley, Katherine. 2003. "Success and Knowledge-How." American Philosophical Quarterly 40: 19-31.

Hetherington, Stephen. 2006. "How to Know (that Knowledge-That is KnowledgeHow)." In Epistemology Futures, ed. S. Hetherington, 71-94. Oxford: Oxford University Press.

Hintikka, Jaakko. 1975. "Different Constructions in Terms of the Basic Epistemological Verbs. A Survey of Some Problems and Proposals." In J. Hintikka, The Intentions of Intentionality and Other New Models for Modalities. Dordrecht: Reidel: 1-25.

Karttunen, L. 1977. "Syntax and Semantics of Questions." Linguistics and Philosophy 1: 3-44.

Koethe, John. 2002. "Stanley and Williamson on Knowing How." The Journal of Philosophy 99: 325-328.

Lehrer, Keith. 1990. Theory of Knowledge. Boulder: Westview Press.

Lewis, David. 1999. "What Experience Teaches", In D. Lewis, Papers in Metaphysics and Epistemology. Cambridge: Cambridge University Press: 262-290.

Liddell, Henry George, and Robert Scott. 1996. A Greek-English Lexicon, with a revised supplement. Oxford: Clarendon Press.

Lihoreau, Franck. 2008. "Knowledge-How and Ability." Grazer Philosophische Studien 77 (1): 263-305.

McGinn, Colin. 1984. "The Concept of Knowledge." Midwest Studies in Philosophy 9: 529554.

Noë, Alva. 2005. “Against Intellectualism.” Analysis 65: 278-290.

Polanyi, Michael. 1958. Personal Knowledge. Towards a Post-Critical Philosophy (corrected edition 1962). Chicago: University Press.

Putnam, Hilary. 1996. "Introduction." In The Twin Earth Chronicles, ed. A. Pessin, and S. Goldberg. Armonk, NY: Sharpe.

Roland, Jane. 1958. “On 'Knowing How' and 'Knowing That'.” Philosophical Review 67: 379388.

Rosefeldt, Tobias. 2004. "Is Knowing-how Simply a Case of Knowing-that?" Philosophical Investigations 27: 370-379.

Rumfitt, Ian. 2003. "Savoir faire." The Journal of Philosopby 100: 158-164.

Ryle, Gilbert. 1945/6. "Knowing How and Knowing That." Proceedings of the Aristotelian Society 46, 1945-46: 1-16 (also in: G. Ryle. Collected Papers, vol. 2, Collected Essays 19291968. London 1971: 212-225).

Ryle, Gilbert. 1949. The Concept of Mind. Chicago: University Press.

Schiffer, Steven. 2002. "Amazing Knowledge." The Journal of Philosophy 99: 200-202.

Stanley, Jason, and Williamson, Timothy. 2001. "Knowing How." The Journal of Philosophy 98: 411-444.

Williams, John N. 2008. "Propositional Knowledge and Know-How." Synthese 165: 107125. 